\title{
Immune Thrombocytopenia Resolved by Eltrombopag in a Carrier of Glucose-6-Phosphate Dehydrogenase Deficiency
}

\author{
Glukoz-6-Fosfat Dehidrogenaz Eksikliği Tașıyıcısında Eltrombopag Yanıtlı Immün Trombositopeni
}

Laura Scaramucci, Pasquale Niscola, Massimiliano Palombi, Andrea Tendas, Marco Giovannini, Paolo de Fabritiis

Sant'Eugenio Hospital, Clinic of Hematology, Rome, Italy

To the Editor,

Eltrombopag, a thrombopoietin mimetic peptide, may provide excellent clinical efficacy in steroid-refractory patients with immune thrombocytopenic purpura (ITP) [1,2]. Eltrombopag is generally well tolerated. However, its use in the particular setting of glucose-6-phosphate dehydrogenase (G6PD) and history of acute hemolytic anemia (AHA) has not been reported so far. A 51-year-old female was diagnosed as having ITP in September 2014. She was not taking any medication and her past history was negative, apart from having been diagnosed a carrier (heterozygous) of G6PD deficiency (Mediterranean variant) after a familial screening by molecular and biochemical methods. She presented with only slightly reduced (about 50\%) enzyme level, belonging to World Health Organization-defined class $3[3,4]$. In the following years, the patient experienced some episodes of AHA, which were managed at outside institutions; in particular, a severe episode of AHA, probably triggered by urinary infection and antibiotics [5], had complicated her second and last delivery. The hemolytic episodes were selflimiting and resolved without sequelae. No other causes of hemolysis were documented. When the case came to our attention, a diagnosis of ITP was made; hemolytic parameters were normal, although the G6PD enzyme concentration was not measured. Oral prednisone $(1 \mathrm{mg} / \mathrm{kg})$ was given with only a transient benefit. The patient was then a candidate for elective splenectomy. However, given her extremely low platelet count, she was started in October 2014 on eltrombopag at 50 $\mathrm{mg} /$ day as a bridge to splenectomy. Given that, to the best of our knowledge, the use of this drug has never been reported in the particular setting of G6PD deficiency, the patient was constantly monitored. A prompt platelet increase (178x109/L) was observed 1 week after the start of treatment. After she achieved the target platelet count, the dose of eltrombopag was tapered to the lowest effective dose. The patient's response was stabile while she remained on a dose of eltrombopag between 25 and $50 \mathrm{mg} /$ day without any adverse events; in particular, no variations of hemolytic parameters were observed. As of today, after 6 months of continuous eltrombopag administration, the patient has constantly maintained the target platelet counts and she is awaiting elective splenectomy. According to our knowledge, we report for the first time the evidence regarding the safe use of this thrombomimetic agonist, which provided an excellent treatment outcome without any adverse effects, in a steroid-refractory adult ITP patient at risk of drug-induced AHA as a G6PD-deficient heterozygous carrier. G6PD deficiency is an X-linked, hereditary genetic defect $[2,3,4]$ for which heterozygous women, who are usually asymptomatic, have a mosaicism of normal and G6PD-deficient erythrocytes. Given the possible decreased amount of G6PD enzyme, although exceptional and only under particularly stressing conditions, such as urinary tract infections and/or the use of certain antibiotics such as nitrofurantoin, AHA may occur [5]. Although our report, being limited to a single patient, is purely anecdotal, considering the high prevalence of G6PD deficiency and the increasing use of thrombomimetic drugs, further collection of such cases would be very useful to determine the complication risks associated in this setting with the use of thrombopoietin agonists.

Keywords: Idiopathic thrombocytopenic purpura, Glucose-6phosphate dehydrogenase deficiency, Thrombopoietin mimetic peptide, TMP mimetic peptide

Anahtar Sözcükler: İdiyopatik immün trombositopeni, Glukoz6-fosfat dehidrogenaz eksikliği, Trombopoetin uyarıcı peptit, TPO uyarıc peptit

\section{Authorship Contributions}

Concept: Laura Scaramucci, Pasquale Niscola, Massimiliano Palombi, Andrea Tendas, Marco Giovannini, Paolo de Fabritiis, Design: Laura Scaramucci, Pasquale Niscola, Massimiliano Palombi, Andrea Tendas, Marco Giovannini, Paolo de Fabritiis, Data Collection or Processing: Laura Scaramucci, Marco Giovannini, Analysis or Interpretation: Laura Scaramucci, Pasquale Niscola, Marco Giovannini, Literature Search: Pasquale Niscola, Massimiliano Palombi, Andrea Tendas, Writing: Laura Scaramucci, Pasquale Niscola, Final Approval: Paolo de Fabritiis.

Conflict of Interest: The authors of this paper have no conflicts of interest, including specific financial interests, relationships, and/or affiliations relevant to the subject matter or materials included. 


\section{References}

1. Tripathi AK, Shukla A, Mishra S, Yadav YS, Yadav DK. Eltrombopag therapy in newly diagnosed steroid non-responsive ITP patients. Int J Hematol 2014;99:413-417.

2. Luzzatto L, Seneca E. G6PD deficiency: a classic example of pharmacogenetics with on-going clinical implications. Br J Haematol 2014;164:469-480.
3. No authors listed. Glucose-6-phosphate dehydrogenase deficiency. WHO Working Group. Bull World Health Organ 1989;67:601-611.

4. Cappellini MD, Fiorelli G. Glucose-6-phosphate dehydrogenase deficiency. Lancet 2008;371:64-74.

5. van de Mheen L, Smits SM, Terpstra WE, Leyte A, Bekedam DJ, van den Akker ES. Haemolytic anaemia after nitrofurantoin treatment in a pregnant woman with G6PD deficiency. BMJ Case Rep 2014:2014.

\title{
Wernicke's Encephalopathy in an Acute Myeloid Leukemia Patient: A Case Study
}

\author{
Bir Akut Myeloid Lösemi Hastasında Wernicke Ensefalopatisi: Bir Olgu Sunumu
}

\author{
Muhammet Maden1, Gülsüm Pamuk1, Yahya Çelik2, Ercüment Ünlü3 \\ 1Trakya University Faculty of Medicine, Department of Hematology, Edirne, Turkey \\ 2 Trakya University Faculty of Medicine, Department of Neurology, Edirne, Turkey \\ ${ }^{3}$ Trakya University Faculty of Medicine, Department of Radiodiagnostics, Edirne, Turkey
}

To the Editor,

Wernicke's encephalopathy (WE) is a life-threatening disease with acute onset, resulting from thiamine deficiency. Causes are alcohol intake, malnutrition, gastric bypass surgery, human immunodeficiency virus infection, total parenteral nutrition (TPN), chronic dialysis, and cancer [1]. WE may cause neurological symptoms such as nystagmus, ophthalmoplegia, ataxia, confusion, convulsions, delirium, coma, and acute psychoses [2].

An 18-year-old female patient with refractory acute myeloid leukemia (AML) was given FLAG-IDA (fludarabine, cytosine arabinoside, idarubicin) chemotherapy protocol. As she developed typhlitis, oral intake was stopped; broad-spectrum antibiotics and TPN without any vitamin supplementation were started. She developed a fixed look to a point, chin and upper extremity spasms, and urinary incontinence on the $38^{\text {th }}$ day of chemotherapy. Neurological examination showed nonlateralization, bilateral light reflexes were $+/+$, verbal stimuli were negative, and the reflex response to painful stimuli was positive. Laboratory results showed hemoglobin of $7.2 \mathrm{~g} / \mathrm{dL}$, leukocytes of $3380 / \mathrm{mm}^{3}$, neutrophils of $2890 / \mathrm{mm}^{3}$, platelets of $48,000 / \mathrm{mm}^{3}$, and normal blood biochemistry. The level of serum thiamine could not be measured, because the laboratory did not have the capabilities to measure it. Brain diffusion MRI showed increased signal intensity in the medial thalami (Figure 1). The patient was diagnosed with WE. She was given 1500 mg/day thiamine i.v. for 3 days and $250 \mathrm{mg} /$ day thiamine i.v. for another 5 days. On the fourth day of thiamine infusion, her general condition began to improve and she started giving one-word responses to verbal stimuli. Her convulsions disappeared and she started to form short sentences and walk without assistance; she was discharged on the $30^{\text {th }}$ day of thiamine replacement therapy. Currently, 2 years have passed since the WE and the patient is in complete hematologic remission.

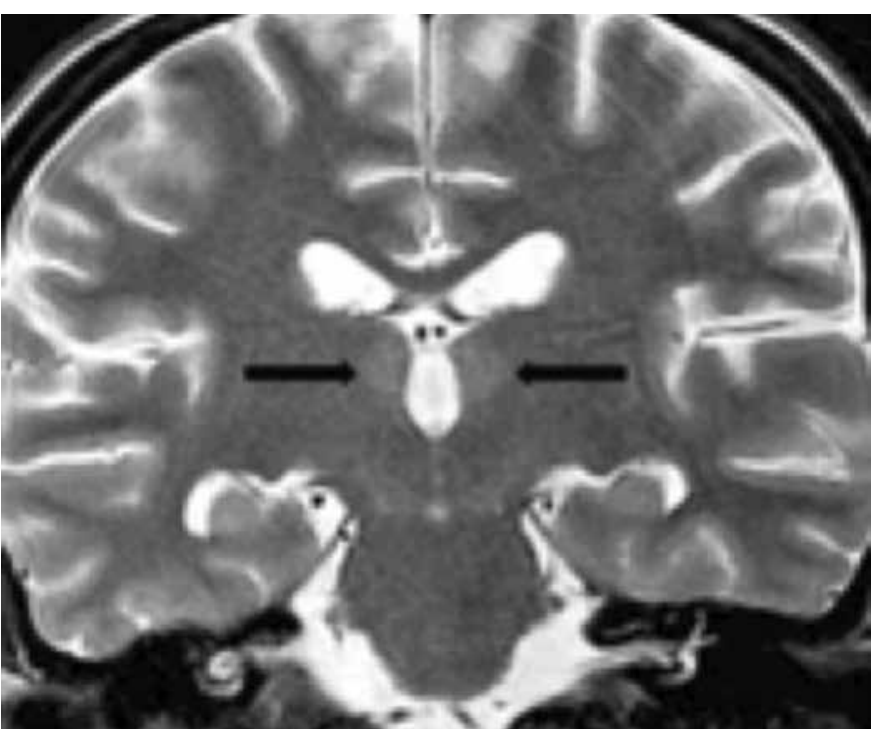

Figure 1. Coronal T2-weighted image shows symmetrical, weak, and limited increased signal intensity in the medial thalami and in the third ventricle-facing surface. 